\title{
JOSÉ LIRA
}

Em 1923, o jovem ucraniano Gregori Warchavchik desembarcou no Brasil após um período de 4 anos na Itália, para onde foi refugiar-se da revolução russa e terminar seus estudos em arquitetura no Regio Istituto Superiore di Belle Artif. Em São Paulo, após um período de trabalho na Companhia Construtora de Santos, começou a tomar contato com o círculo modernista da arte brasileira, fator decisivo para o fomento de suas ideias sobre arquitetura moderna e para a realização do primeiro manifesto do país sobre este tipo de arquitetura, publicado em 1925. Anos depois, casado com Mina Klabin, Warchavchik realizou a primeira construção modernista do Brasil, obra pela qual ficaria mais conhecido: a casa modernista da Rua Santa Cruz, em São Paulo.

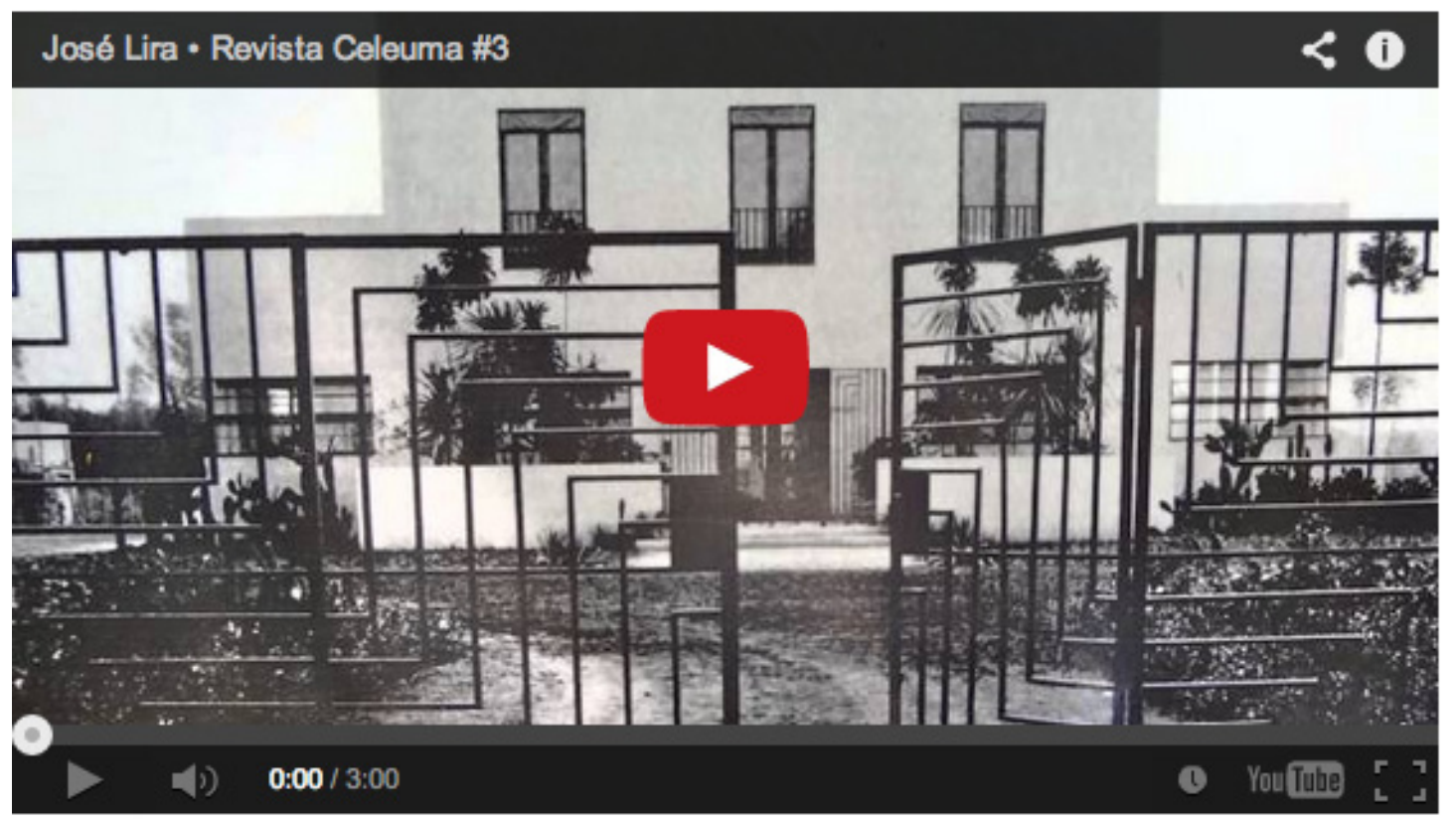

A exposição Warchavchik - metrópole, arquitetura, em cartaz no Centro Universitário Maria Antonia, traça um vasto panorama da produção do arquiteto, tendo como foco sua relação com a cidade e seus projetos menos conhecidos. Curada por José Lira, professor da Faculdade Arquitetura e Urbanismo da USP, a mostra nasceu a partir da pesquisa para a tese de livre docência que ele desenvolveu nos últimos anos e que se desdobrou também em livro (Warchavchik: fraturas da vanguarda, Cosac Naify, 2011). 
Abdicando de projetos para habitações burguesas, como a famosa casa modernista, e centrando-se naqueles de natureza coletiva realizados por Warchavchik, a exposição oferece uma "leitura da arquitetura a partir de seu lugar na cidade", segundo o curador. São exibidos nessa seleção, principalmente, projetos realizados entre o começo da década de 1930 até o final dos anos 1950. As imagens estão organizadas em quatro seções: conjuntos de habitação, espaços de recreação e lazer, edifícios de grandes apartamentos e edifícios comerciais.

"Procuramos fazer um recorte que, sem sacrificar o fato da exposição provir de uma pesquisa, e as possibidades de trazer elementos e leituras originais, fosse mais acessível a um público extra-aquitetônico", afirma Lira.

Sendo assim, foram escolhidas imagens que apresentassem uma "representação gráfica mais simples".

"Ao invés de desenhos técnicos, foram privilegiadas as perspectivas, as imagens externas dos edifícios, sem as abstrações gráficas dos desenhos arquitetônicos." Dentro deste raciocínio, a curadoria abriu mão de maquetes e optou por inserir imagens mais presentes na cultura popular: são cenas de filmes de época, notas da imprensa de arquitetura e anúncios de lançamentos imobiliários que retratam as transformações que a cidade sofreu nas últimas décadas. Há também duas pequenas vitrines que destacam pontos importantes da vida de Warchavichik.

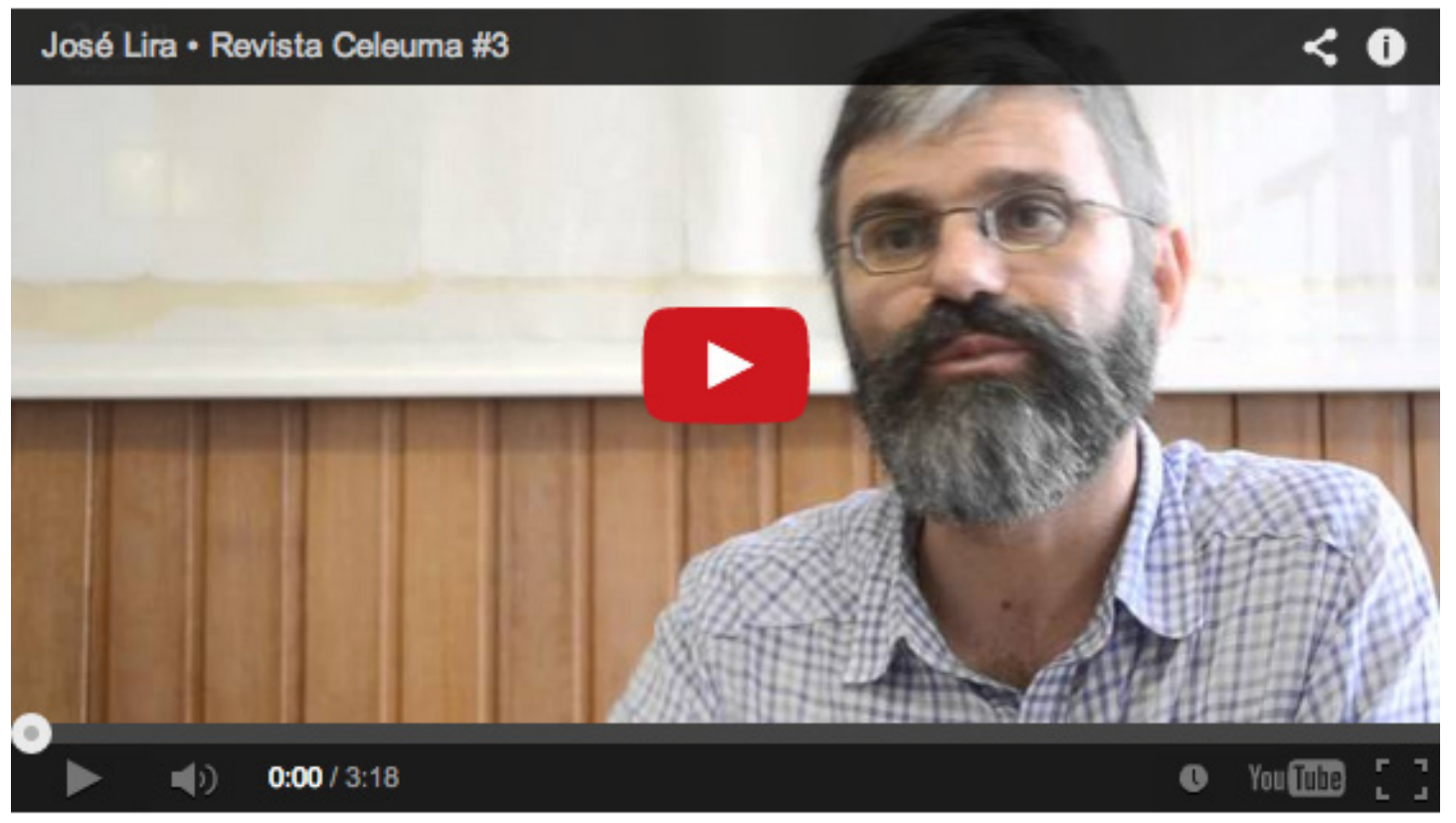

A exposição foi viabilizada por meio de uma parceria entre a biblioteca de projetos da FAU-USP, que abriga, desde a década de 80, o acervo do antigo 
escritório Gregori Warchavick, e o Centro Universitário Maria Antonia. Os mais de vinte e oito projetos selecionados passaram por um processo de restauro que contou com o auxílio de funcionários do IEB (Instituto de Estudos Brasileiros da USP) e da própria FAU.

"Para mim e para as demais pessoas envolvidas na realização da exposição, foi um desafio transformar um trabalho especializado em algo público a ser exposto; um momento de reflexão sobre a necessidade do trabalho de arquivo com documentos, com originais", completa José Lira.

por Thierry Freitas. 